\title{
Carotid free-floating thrombus treated with apixaban: report of a case and review of literature
}

\author{
Carlos A. Soto-Rincón ${ }^{1}$, Sergio A. Castillo-Torres ${ }^{1}$, Alejandro Gonzalez-Aquines ${ }^{1}$, Iris C. Farías-Navarro², \\ Emmanuel J. Escobar-Valdivia', Erik A. García-Valadez ${ }^{1,3}$, Beatriz E. Chávez-Luévanos ${ }^{1}$ and \\ Fernando Góngora-Rivera ${ }^{1,3 *}$
}

${ }^{1}$ Neurology Service; ${ }^{2}$ Department of Internal Medicine; ${ }^{3}$ Neurovascular Care Unit, Hospital Universitario “Dr. José E. González". Universidad Autónoma de Nuevo León, Monterrey, Nuevo León, Mexico

\begin{abstract}
Free-floating thrombus of the internal carotid artery is infrequent (< $1 \%$ of strokes), although its diagnosis is straightforward, its treatment represents a challenge. Based mostly on case reports, standard treatment consists of therapeutic anticoagulation, while waiting for carotid endarterectomy. Both unfractioned heparin and Vitamin $\mathrm{K}$ antagonists have been reported as efficaceous; nevertheless, due to its rarity, clinical trials with novel oral anticoagulants are lacking. We report a patient with cardioembolic stroke and a free-floating carotid thrombus successfully treated with apixaban.
\end{abstract}

Key words: Free-Floating Thrombus. Stroke. Novel oral anticoagulants.

\section{Trombo libre flotante de la arteria carótida tratado con apixaban: revisión basada en un caso}

\section{Resumen}

Los trombos libres flotantes de la arteria carótida interna son infrecuentes (menos del 1\% de los ictus), y representan un desafío terapéutico. El tratamiento actual, basado en series de casos, consiste en anticoagulación terapéutica en espera de endarterectomía. Tanto la heparina no fraccionada, como los antagonistas de vitamina $K$, han sido reportados como eficaces. Sin embargo, dada la escasez de casos, no se dispone de ensayos clínicos con nuevos anticoagulantes orales. Reportamos el caso de un paciente con ictus cardioembólico y un trombo libre flotante de la carótida, tratado exitosamente con apixaban.

Palabras clave: Trombo libre flotante. Ictus. Nuevos anticoagulantes orales.

\section{Correspondence:}

${ }^{*}$ Fernando Góngora-Rivera

Unidad de Cuidados Neurovasculares

Servicio de Neurología

Departamento de Medicina Interna

Hospital Universitario "Dr. Jose E. Gonzalez"

Madero y Gonzalitos, s/n

Col. Mitras Centro

Date of reception: 11-03-2019

C.P. 64460 , Monterrey, NL, México

E-mail: fernando.gongora@ @otmail.com
Available online: 03-02-2020

Rev Mex Neuroci. 2020;21(1):27-30

www.revmexneurociencia.com (http://creativecommons.org/licenses/by-nc-nd/4.0/). 


\section{Introduction}

A free-floating thrombus (FFT) of the carotid artery is defined as "an elongated thrombus attached to the arterial wall with circumferential blood flow at its distal most aspect with cyclical motion relating to cardiac cycles"1. They are infrequently found in patients with stroke and are associated with large artery atherosclerosis, in which the rupture of an unstable plaque results in an intraluminal thrombus that in most of the cases dislodges and embolized causing ischemia on distal arterial beds; however, there are cases in which the thrombus remains attached to the plaque, giving origin to the FFT. The absence of randomized clinical trials due to scarcity of cases makes acute treatment and secondary prevention a challenge. We describe one patient with cardioembolic stroke and a FFT of the carotid artery, successfully treated with apixaban. We describe a patient with cardioembolic stroke and large artery atherosclerosis with a FFT of the carotid artery, successfully treated with apixaban.

\section{Clinical case}

A 69-year-old male of Mexican descent, active smoker (7 pack-per-year), with 20-year history of uncontrolled diabetes mellitus and hypertension is admitted to the neurovascular care unit for etiological assessment of left anterior choroidal artery and middle cerebral artery ischemic stroke, with a NIHSS 14. Treatment with aspirin, atorvastatin, and prophylactic unfractionated heparin (UFH) is started. Etiology is ascertained as cardioembolism (paroxysmal atrial fibrillation with left-atrial appendage thrombus echocardiogram); and extracranial large-artery atherosclerosis (left internal carotid artery occlusion of $70 \%$ ) confirmed with Doppler sonogram and computed tomography angiography (CTA) which revealed a FFT attached to an heterogeneous plaque, with a "doughnut sign" (Fig. 1). Due to distal embolization concerns, endarterectomy is delayed; and 7 days after stroke-onset, UFH is suspended, and after consensus with the neurovascular unit team, apixaban (5 $\mathrm{mg}$ bid) started as secondary prevention measure. After 4 days, control CTA shows no evidence of FFT (Fig. 2); absence of neurological worsening and additional strokes on imaging, ruled out distal embolization. Incidentally, a pituitary prolactinoma was found, along with thyroid papillary neoplasia; hormonal profile was normal, which ruled out multiple endocrine neoplasia.

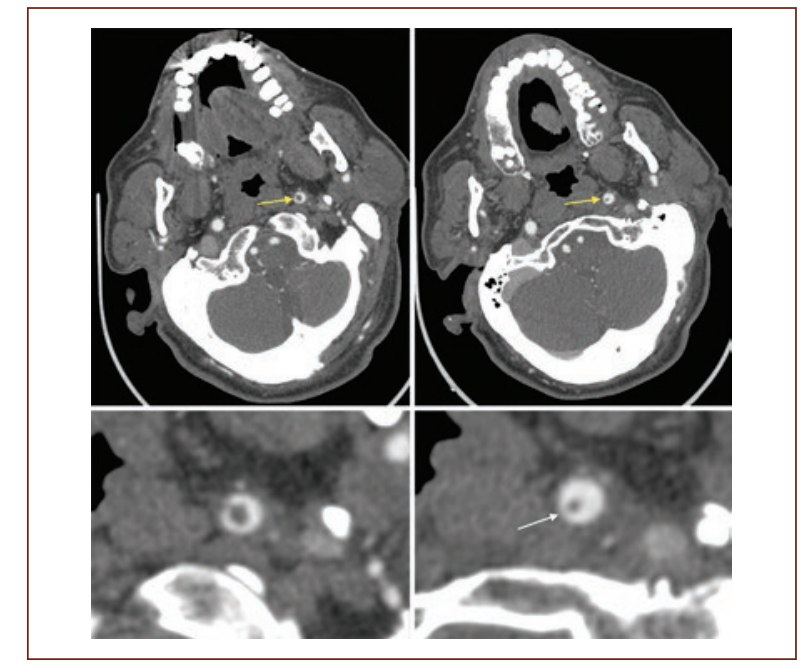

Figure 1. Computed tomography angiography showing free-floating thrombus on the left internal carotid artery (yellow arrow), with donut sign (white arrow, detail, lower panels).

After observation, without improvement of neurological deficit despite early physical therapy, the patient is discharged with NIHSS 13, modified Rankin scale (mRs) 3, and apixaban $5 \mathrm{mg}$ twice daily. At 90-days follow-up, neurological deficit persists, with NIHSS 11 points and mRs 2 despite physical therapy. A control echocardiogram and procoagulant profile were proposed, yet patient refused, and were lost at 6-month follow-up.

\section{Discussion}

We present the first case of a FFT treated with apixaban, a novel oral anticoagulant, acting as direct Xa factor inhibitor. FFT is an uncommon entity, reported in $<1 \%$ of stroke patients $(0.004 \%-0.9 \%)^{2,3}$, and its appearance on axial projections has been referred to in the literature as the "doughnut sign" (Fig. 1). Although digital-subtraction angiography is considered the diagnostic gold standard, there are no formal diagnostic criteria, and the FFT can be identified on $\mathrm{CTA}^{4}$, and we agree with the definition by Bhatti et al. ${ }^{1}$ Pathophysiology that explains FFT is lacking; however, we hypothesize that it is a two-hit mechanism, needing a ruptured unstable atherosclerotic plaque on the carotid artery, and a hypercoagulable state (as a cardiac source of embolism) that fosters thrombus adherence and elongation. This hypothesis is supported by the fact that 


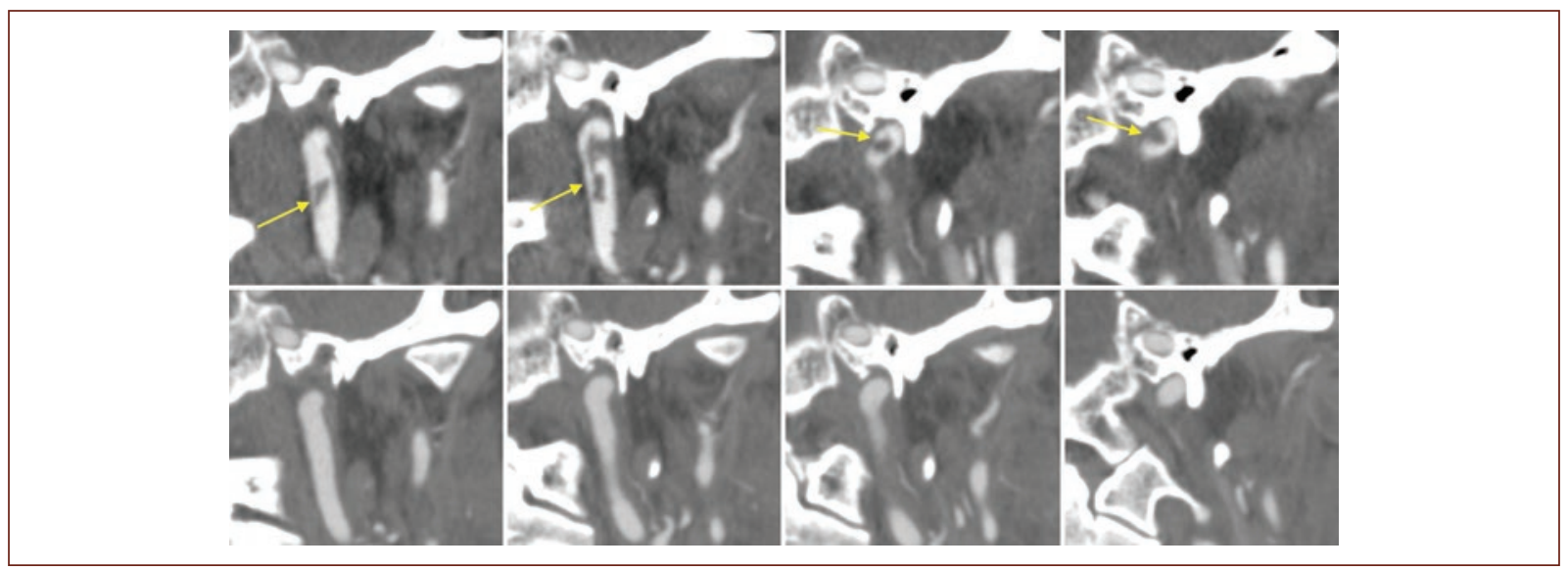

Figure 2. Computed tomography angiography coronal reconstruction, showing free-floating carotid thrombus before (yellow arrow, upper panels) and after treatment with apixaban, without thrombus evidence (lower panels).

Table 1. Reported cases of carotid free-floating thrombus disappearance

\begin{tabular}{|c|c|c|c|c|}
\hline References & Stroke etiology & Treatment & Resolution (time) & Outcome \\
\hline Bhatti et al. ${ }^{1 *}$ & Undeterminate & VKA & NR & NR \\
\hline \multirow[t]{3}{*}{ Chua et al. ${ }^{3}$} & Lacunar stroke & VKA & 4 months & NR \\
\hline & Lacunar stroke & VKA & 2 months & NR \\
\hline & Lacunar stroke & VKA & 14 days & NR \\
\hline Yonemura et al. ${ }^{4}$ & Cardioembolism & UFH, then VKA & 2 weeks & $\begin{array}{l}\text { No additional } \\
\text { neurological impairment }\end{array}$ \\
\hline \multirow[t]{2}{*}{ Elijovich et al. ${ }^{5}$} & Lupus anticoagulant** & VKA & 7 days & $\begin{array}{l}\text { No additional } \\
\text { neurological impairment }\end{array}$ \\
\hline & Not specified & UFH & 5 days & $\begin{array}{l}\text { No additional } \\
\text { neurological impairment }\end{array}$ \\
\hline Sallustio et al. ${ }^{6}$ & Atherothrombosis (Ruptured plaque) & UFH & 10 days & No FFT recurrence \\
\hline Graham et al..$^{10}$ & Undeterminate & UFH, then VKA & 41 months & NR \\
\hline Bajko et al. ${ }^{11}$ & Undeterminate & LMWH, then ASA & 7 days & NR \\
\hline Frías Vargas et al. ${ }^{12}$ & Atherosclerosis & LMWH & 25 days & $\begin{array}{l}\text { No additional } \\
\text { neurological impairment }\end{array}$ \\
\hline Tanriverdi et al. ${ }^{13}$ & Not specified & UFH & 7 days & $\begin{array}{l}\text { No additional } \\
\text { neurological impairment }\end{array}$ \\
\hline Castillo-Torres et al. $^{\dagger}$ & $\begin{array}{l}\text { Atherothrombosis and } \\
\text { Cardioembolism }\end{array}$ & DFXal & 4 days & $\begin{array}{l}\text { No additional } \\
\text { neurological impairment }\end{array}$ \\
\hline
\end{tabular}

*Report of 24 cases. ${ }^{* *}$ Mentioned as finding. ${ }^{\dagger}$ Actual case. ASA: acetylsalicylic acid; VKA: Vitamin K Antagonist; LMWH: low molecular weight heparin; UFH: unfractionated heparin; DFXal: direct factor Xa inhibitor; NR: not reported.

FFT has been reported in association with procoagulant factors as lupus anticoagulant ${ }^{5}$.

Given its scarcity, there are no guidelines for therapeutic management. The most commonly reported protocol is therapeutic anticoagulation with either UFH or Vitamin $\mathrm{K}$ antagonists (VKA) while waiting for endarterectomy. Nevertheless, therapeutic anticoagulation alone has been reported effective in up to $85 \%$ of cases ${ }^{1,3}$ with thrombus recurrence after discontinuation of anticoagulants ${ }^{6}$. There are no randomized trials to demonstrate superiority of 
either UFH or VKA, and until our report, novel oral anticoagulants (like apixaban) had not been used for this entity. Whether temporary or definitive, anticoagulation is needed, and typically is withdrawn when a cause for longterm therapy is ruled out, and thrombus resolution is demonstrated; although the optimal time to repeat imaging is uncertain, carotid ultrasound could be used as screening method. Monotherapy with antiplatelet agents is not recommended, as it has been associated with carotid oclussion ${ }^{3}$. Furthermore, novel endovascular therapeutic approaches have been reported as effective in the treatment of $\mathrm{FFT}^{7,8}$.

Although dislodgment and distal embolization of thrombus could explain thrombus disappearance, the absence of clinical and radiological worsening, speak in favor of apixaban-related resolution. Thrombus disappearance has been scarcely documented, with 35 cases reported to date ${ }^{1,3,5,6,9-13}$ (Table 1). Nevertheless, we must acknowledge there are other potential confounding factors, such as prophylactic UFH contribution, which could suggest apixaban was not the sole responsible; yet, until better evidence is available, our case report speaks in favor of direct Xa factor inhibitors as an alternative to UFH and VKA.

\section{Conclusion}

Carotid FFT is an uncommon entity that can be successfully treated with novel oral anticoagulants.

\section{Contributorship statement}

CASR contributed to the conception and design of the manuscript, data acquisition and drafting of the first manuscript. SACT contributed to design of the manuscript, data analysis and interpretation and critical review of the first manuscript. AGA contributed to conception and design of the manuscript, data acquisition and drafting of the first manuscript. ICFN contributed to data acquisition and analysis and interpretation, and critical review of the first manuscript, EJEV contributed to conception of the manuscript, data analysis and interpretation and critical review of the first manuscript, EAGV contributed to conception of the manuscript, data analysis and interpretation and critique of intellectually relevant content the manuscript. BECL contributed to design of the manuscript, data analysis and interpretation, and critique of intellectually relevant content the manuscript. FGR contributed to conception and design of the manuscript, data analysis, and interpretation and critique of intellectually relevant content the manuscript, providing the expert's opinion on the use of novel oral anticoagulants in difficult cases. All authors agreed on the final form of the manuscript.

\section{Funding}

The authors declare no relevant funding for this manuscript.

\section{Conflicts of interest}

None to declare.

\section{Ethical disclosures}

Protection of human and animal subjects. The authors declare that no experiments were performed on humans or animals for this study.

Confidentiality of data. The authors declare that they have followed the protocols of their work center on the publication of patient data.

Right to privacy and informed consent. The authors have obtained the written informed consent of the patients or subjects mentioned in the article. The corresponding author is in possession of this document.

\section{References}

1. Bhatti AF, Leon LR Jr., Labropoulos $N$, Rubinas $T L$, Rodriguez $H$, Kalman PG, et al. Free-floating thrombus of the carotid artery: literature review and case reports. J Vasc Surg. 2007;45:199-205.

2. Biller J, Adams HP Jr., Boarini D, Godersky JC, Smoker WR, Kongable G, et al. Intraluminal clot of the carotid artery. A clinical-angiographic correlation of nine patients and literature review. Surg Neurol. 1986;25:467-77.

3. Chua HC, Lim T, Teo BC, Phua Z, Eng J. Free-floating thrombus of the carotid artery detected on carotid ultrasound in patients with cerebral infarcts: a 10-year study. Ann Acad Med Singapore. 2012;41:420-4.

4. Ferrero E, Ferri M, Viazzo A, Labate C, Pecchio A, Berardi G, et al. Free-floating thrombus in the internal carotid artery: diagnosis and treatment of 16 cases in a single center. Ann Vasc Surg. 2011;25:805-12.

5. Elijovich L, Mainali S, Doss V, Arthur A, Watridge C. Medical management of free-floating carotid thrombus. Clin Neurol Neurosurg. 2013:115:1532-5.

6. Sallustio F, Di Legge S, Marziali S, Ippoliti A, Stanzione P. Floating carotid thrombus treated by intravenous heparin and endarterectomy. J Vasc Surg. 2011;53:489-91.

7. Carr K, Tew D, Becerra L, Siddall K, Dubensky L, Serulle Y, et al. Endovascular aspiration of a symptomatic free-floating common carotid artery thrombus. Neuroradiology. 2018;60:1103-7.

8. Fitzpatrick N, Motyer R, Gibney B, Duffy S, Murphy S, O'Brien P, et al. Expanding the role of stent-retriever endovascular thrombectomy: a case series of free-floating thrombus. J Neurointerv Surg. 2018;10:1164-7.

9. Yonemura K, Kimura K, Yasaka M, Minematsu K. Disappearance of an oscillating intraluminal thrombus in the carotid artery demonstrated by ultrasonography. Intern Med. 2003;42:746-9.

10. Graham R, Blaszczynski M. Spontaneous free floating carotid artery thrombosis. BMJ Case Rep. 2013;2013:bcr2013008710.

11. Bajkó Z, Maier S, Rusu S, Moțățăianu A. Acute ischaemic stroke secondary to a mobile thrombus in the common carotid artery - case report. J Crit Care Med (Targu Mures). 2015;1:68-70.

12. Frías Vargas M, Tavera Santos E, Carrasco Carrasco E, López Uriarte B. Free floating thrombus in the internal carotid and vascular risk: presentation of a case. Semergen. 2016;42:274-6.

13. Tanriverdi U, Kizilkilic O, Ince B. Huge free-floating thrombus in the internal carotid artery. J Stroke Cerebrovasc Dis. 2017;26:3029-30. 